\title{
ANALISIS SISTEM PEMETIKAN KOPI SELEKTIF DAN RACUTAN TERHADAP PENDAPATAN PETANI KOPI DI KABUPATEN OKU SELATAN
}

\author{
(Hariyono)
}

\begin{abstract}
The purpose of this research were to: (1) Determine the cost, revenue, and revenue and profits farmers Robusta coffee with a system of selective and racutan in the district of South OKU, (2) Knowing How large is the ratio of income between the system of picking racutan with the system picking selective in the district of South OKU, (3) Determine the financial feasibility of picking coffee farming system and picking racutan selective system in the district of South OKU. This research was conducted in the District of South OKU. This study was conducted in May and June 2013, with a survey and disproporsionated purposive sampling method, and also took 99 samples. This study found that coffee farming Acceptance by picking racutan system $R p$ 19,548,148, - / LG and Rp 16,250,776, - / ha, costs $R p$ 9,159,264, - / LG and Rp 7,578,429, - / ha, the coffee farming with picking system racutan earn $R p$ 10,388,884, - / LG and 8,672,347, / ha, whereas usatahani picking coffee with selective system gained acceptance $R p$ 20,029,412, - / LG and Rp 17,241,947, - / Ha, costs Rp 10.49065 million, - / LG and Rp 8,806,712, - / ha, then the coffee farm picking system selectively obtain revenue of $R p$ 9,538,762, - / LG and $R p$ 8,435,234, - / Ha.
\end{abstract}

Key Words : Coffee processing system, income.

\section{PENDAHULUAN}

\section{A. Latar Belakang}

Kopi merupakan salah satu hasil komoditi perkebunan yang memiliki nilai ekonomis yang cukup tinggi di antara tanaman perkebunan lainnya dan berperan penting sebagai sumber devisa negara. Kopi tidak hanya berperan penting sebagai sumber devisa melainkan juga merupakan sumber penghasilan bagi tidak kurang dari satu setengah juta jiwa petani kopi di Indonesia (Rahardjo, 2012).

Usaha tani kopi di Indonesia pada umumnya dilakukan pada lahan yang luas maupun lahan yang sempit atau di pekarangan rumah. Usaha tani kopi yang dilakukan pada lahan yang luas bertujuan komersil untuk mengharapkan keuntungan (Yusianto, 2010).

Saat ini, peningkatan produksi kopi di Indonesia masih terhambat oleh rendahnya mutu biji kopi yang dihasilkan sehingga mempengaruhi pengembangan produksi akhir kopi. Hal ini disebabkan, karena penanganan pemetikan dan pasca panen yang tidak tepat antara lain pemetikan, proses fermentasi, pencucian, sortasi, pengeringan, dan penyangraian. Selain itu spesifikasi alat/mesin yang digunakan juga dapat mempengaruhi setiap tahapan pengolahan biji kopi.

Oleh karena itu, untuk memperoleh biji kopi yang bermutu baik maka diperlukan pemetikan yang tepat dengan melakukan secara benar. Proses pemetikan merupakan salah satu tahapan yang penting, namun saat ini masih sedikit data tentang bagaimana proses pemetikan yang tepat untuk menghasilkan buah kopi segar yang berkualitas. Dalam usaha meningkatkan harga jual dan mutu buah kopi maka petani harus memahami pemetikan buah kopi.

Pada dasarnya, ada dua tipe pemetikan kopi. Perbedaan kedua tipe pemetikan kopi ini adalah warna buah ketika panen. Pada racutan, biji kopi dipanen saat masih berwana hijau, kuning, dan merah, sedangkan pemetikan selektif dilakukan dengan memetik biji kopi yang telah berwarna merah. Dari segi kualitas produk kopi, kopi hasil panen selektif menghasilkan biji yang lebih berat dengan bentuk yang lebih besar dan sempurna, rasa lebih enak, tahan lama apabila disimpan di gudang, harga jual lebih tinggi dan banyak diminati perusahaan kopi. Sementara, biji hasil panen racutan cenderung lebih ringan karena bentuk bijinya belum padat, rasa yang dihasilkan kurang memuaskan, tidak tahan lama disimpan, harga jual murah.

Tingkat produktivitas pemetik kopi yang masih belum optimal dan persentase biji kopi hijau terpetik yang relatif tinggi tentu berpengaruh terhadap pencapaian realisasi produksi kopi. Peningkatan realisasi produksi dapat dilakukan dengan mengoptimalkan produktivitas tenaga kerja dan mengurangi jumlah biji kopi hijau yang ikut terpetik. Peningkatan produktivitas kerja akan memberi keuntungan pada semua pihak baik perusahaan maupun tenaga kerja.

Kopi menjadi salah satu komoditi andalan perkebunan di Sumatera Selatan yang 
memberikan kontribusi yang cukup besar bagi perekonomian daerah Sumatera Selatan. Produksi kopi di Sumatera Selatan dihasilkan oleh tiga macam perkebunan, yaitu perkebunan rakyat, perkebunan besar swasta, dan perkebunan milik negara. Dari tiga perkebunan rakyat merupakan penghasil utama komoditas kopi (Hutahean, 2006).

Sebagian besar produksi kopi berasal dari Kabupaten/Kota di Sumatera Selatan, seperti Lahat, Pagar Alam, Muara Enim, Ogan Komering Ulu, Musi Rawas, dan Lubuk Linggau. Terdapat lima daerah sentra produksi kopi di Sumatera Selatan, yaitu secara berturut-turut Kabupaten lahat, Kabupaten OKU Selatan, Kota Pagar Alam, dan Kabupaten Musi Enim. Luas areal perkebunan kopi di kelima daerah tersebut mencapai 94,56 persen dari total area di Sumatera Selatan, sementara produksinya mencapai 93,69 persen (Junaidi, dkk., 2007).

Tabel 1. Luas Areal dan Produksi Kopi Kabupaten OKU Selatan.

\begin{tabular}{ccc} 
Tahun & Luas Tanam $(\mathrm{Ha})$ & Produksi $($ Ton $)$ \\
\hline 2011 & 70799 & $32.949,04$ \\
2012 & 70799 & $32.949,60$ \\
2013 & 70799 & $32.926,78$ \\
2014 & 70799 & $33.174,82$ \\
2015 & 70799 & $32.226,24$ \\
\hline
\end{tabular}

Sumber: Dinas Kehutanan dan Perkebunan.

Kabupaten OKU Selatan merupakan sentra produksi kopi di sumatera selatan, dengan luas lahan yakni mencapai 70.799 ha dengan jumlah produksi pada tahun 2015 sebesar 32.226,24.

Proses pemetikan kopi merupakan proses untuk memperoleh mutu biji yang baik dalam segi kualitas ataupun kuantitas yang dihasilkan. Kualitas kopi yang baik tidak hanya dipengaruhi dari jenis tanaman kopi dan daerah asal penghasilnya saja, namun pola tanam dan perawatan yang dilakukan termasuk perlakuan pada biji kopi ketika panen dan pasca panen menjadi faktor penting yang memengaruhi kualitas biji kopi. Perbedaan perlakuan pada tanaman dan waktu panen inilah yang membuat pembeda karakteristik kopi di pasaran.

Biji kopi kualitas baik adalah biji kopi yang dipanen dalam keadaan matang sempurna, yaitu yang memiliki kulit berwarna merah pada semua bagian sisinya. Hal ini oleh para petani kopi biasa disebut sebagai panen petik merah.

Pada panen biji kopi merah prosesnya harus dilakukan secara selektif, karena kematangan biji kopi tidak terjadi secara serentak dalam satu dompol. Biji kopi yang masih berwarna hijau tetap dibiarkan untuk waktu pemetikan berikutnya, namun hal ini tak menjadi jaminan, karena biji kopi yang telah dipanen juga tetap harus disortir lagi. Proses pemetikan petik merah ini dilakukan dengan tujuan untuk menjaga kematangan agar tidak mengalami perubahan kualitas pada proses pengolahan.

Permainan para tengkulak biji kopi justru membeli biji kopi dari para petani dengan cara petik serentak atau dengan cara racutan. Sehingga panen kopi tidak dilakukan dengan selektif, biji kopi merah dan biji kopi yang masih hijau dipetik secara bersamaan. Pemetikan secara serentak ini akan merusak kualitas biji kopi yang dihasilkan, karena antara biji kopi matang dan muda bercampur menjadi satu. Tengkulak biji kopi bermain pada bobot kopi yang dihasilkan, karena mereka biasanya membeli dalam jumlah banyak tanpa mempertimbangkan kualitas.

\section{B. Rumusan Masalah}

1. Berapa besar biaya, penerimaan, dan pendapatan serta keuntungan yang diperoleh petani kopi Robusta dengan sistem selektif dan racutan di Kabupaten OKU Selatan.

2. Berapa besar perbandingan pendapatan antara sistem pemetikan racutan dengan sistem pemetikan selektif di Kabupaten OKU Selatan.

3. Bagaimana kelayakan finansial dari usahatani kopi pemetikan sistem racutan dan pemetikan sistem selektif di Kabupaten OKU Selatan.

\section{Tujuan dan Kegunaan}

1. Mengetahui biaya, penerimaan, dan pendapatan serta keuntungan yang diperoleh petani kopi Robusta dengan sistem selektif dan racutan di Kabupaten OKU Selatan.

2. Mengetahui Berapa besar perbandingan pendapatan antara sistem pemetikan racutan dengan sistem pemetikan selektif di Kabupaten OKU Selatan.

3. Mengetahui kelayakan finansial dari usahatani kopi pemetikan sistem racutan dan pemetikan sistem selektif di Kabupaten OKU Selatan. 


\section{Model Pendekatan}

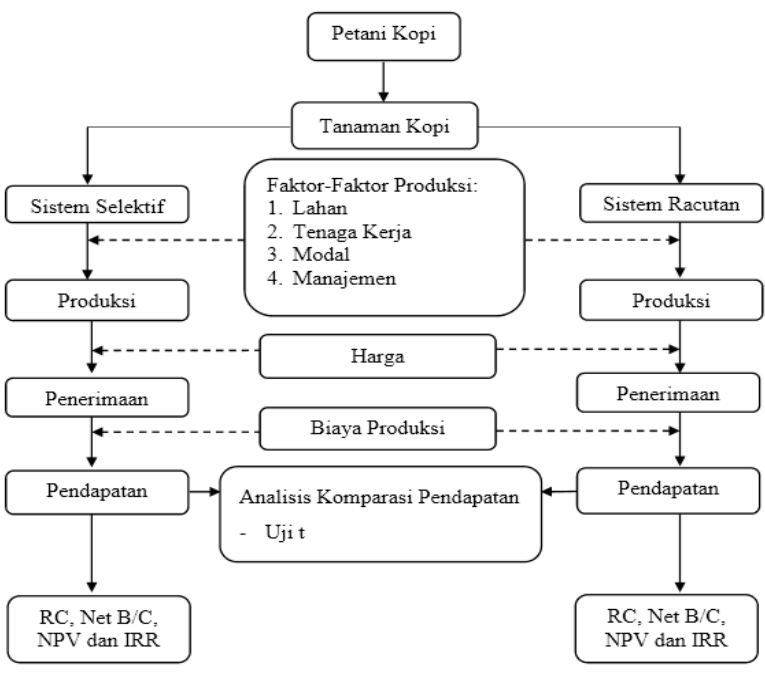

Keterangan:

Mempengaruhi

Dipengaruhi

Gambar 1. Model pendekatan penelitian secara diagramatik

\section{METODOLOGI PENELITIAN}

\section{A. Tempat dan Waktu}

Penelitian ini telah dilaksankan di Kabupaten OKU Selatan. Lokasi penelitian ditentukan secara sengaja (Purposive) dengan pertimbangan bahwa daerah ini terdapat usahatani kopi usaha yang dominan. Penelitian ini telah dilaksanakan pada bulan Mei sampai dengan Juni 2013.

\section{B. Metode Penelitian}

Metode yang digunakan dalam penelitian ini adalah metode survei pada petani kopi di Kabupaten OKU Selatan untuk memperoleh gambaran nyata di lapangan. Metode survei merupakan suatu cara pendekatan dengan menggunakan teknik yang berhubungan dengan survei. Metode ini sering digunakan pada penelitian usahatani (Soekartawi, 2002).

\section{Metode Penarikan Contoh}

Metode penarikan contoh yang digunakan adalah metode Disproportionate Stratified Random Sampling. Disproportionate stratified random sampling adalah pengambilan sampel dari anggota populasi secara acak dan berstrata tetap, sebagian ada yang kurang proporsional pembagiannya. Sugiyono (2012) menyatakan bahwa teknik ini digunakan untuk menentukan jumlah sampel bila populasinya berstrata tetapi kurang proporsional.

Metode ini diambil karena pada setiap usahatani terdapat perbedaan populasi, dimana populasi yang diambil berjumlah 99 petani yang melakukan pemetikan sistem selektif dan racutan.

Penentuan jumlah sampel dilakukan dengan menggunakan rumus Slovin (Sangadji \& Sopiah, 2010) sebagai berikut:

Dimana:

$$
n=\frac{N}{1+N e^{2}}
$$

$\mathrm{n}=$ Jumlah Sampel Penelitian

$\mathrm{N}=$ Jumlah Populasi Penelitian

$\mathrm{e}=$ Nilai kritis yang digunakan $(15 \%)$

Berdasarkan rumus diatas maka jumlah sampel yang dapat mewakili masing-masing populasi adalah sebagai berikut:

1. Sampel petani yang melakukan pemetikan selektif

$n=\frac{27}{1+\left(27 \times 0,15^{2}\right)}=\frac{27}{1,61}=16,80 \approx 17$

2. Sampel petani yang melakukan pemetikan racutan

$n=\frac{72}{1+\left(72 \times 0,15^{2}\right)}=\frac{72}{2,62}=27,48 \approx 27$

Dari hasil perhitungan diatas, peneliti memiliki asumsi bahwa jumlah sampel minimal yang dapat mewakili populasi dalam penelitian ini adalah sebagai berikut:

Tabel 2. Jumlah populasi dan sampel pemetikan sistem selektif dan racutan

\begin{tabular}{lllll}
\hline No & Pemetikan & Populasi & Sampel & Persentase \\
\hline 1 & Selektif & 27 & 17 & $62 \%$ \\
2 & Racutan & 72 & 27 & $37,5 \%$ \\
\hline
\end{tabular}

Sumber: Data Primer, 2013.

\section{Metode Pengolahan Data}

Data yang dikumpulkan meliputi data primer dan data sekunder. Data primer diperoleh melalui observasi dan wawancara langsung dengan petani.

Data sekunder diperoleh dari dinas-dinas atau instansi yang terkait dalam penelitian ini seperti dinas perkebunan dan pusat statistik, yang meliputi keadaan umum dan data lain yang dapat menunjang penelitian ini.

Data yang telah diperoleh dari penelitian dikelompokan dan kemudian dioleh secara tabulasi: 
1. Untuk menjawab tujuan penelitian yang pertama yaitu:

- Untuk mengetahui biaya, penerimaan dan pendapatan serta keuntungan usahatani kopi maka digunakan rumus sebagai berikut (Suratiyah, K. 2006):

$$
\begin{aligned}
\mathrm{TC} & =\mathrm{FC}+\mathrm{VC} \\
\mathrm{TR} & =\mathrm{Y} \times \mathrm{P} \\
\mathrm{I} & =\mathrm{TR}-\mathrm{TC} \\
\mathrm{R} / \mathrm{C} & =\frac{T R}{T C}
\end{aligned}
$$

Dimana:

$\mathrm{TC}=$ Total Cost/Total Biaya

$\mathrm{TR}=$ Total Reveneu/Total Penerimaan

$\mathrm{I}=$ Income /Pendapatan

$\mathrm{FC}=$ Fixed Cost/ Biaya Tetap

$\mathrm{VC}=$ Variabel Cost $/$ Biaya Tidak Tetap

$\mathrm{Y}=$ Yeild/ Jumlah Produksi

$\mathrm{P}=$ Price/Harga Jual

$\mathrm{R} / \mathrm{C}=$ Perbandingan Total Revenue dengan Total Cost

Kriteria yang dipakai dalam menilai sesuatu usaha ditentukan adalah:

- Jika nilai R/C ratio lebih dari satu $(\mathrm{R} / \mathrm{C}>1)$ maka usahatani tersebut menguntungkan untuk dilaksakanakan.

- Jika nilai $\mathrm{R} / \mathrm{C}$ ratio kurang dari satu $(\mathrm{R} / \mathrm{C}<1)$ maka usahatani tersebut tidak menguntungkan untuk dilaksanakan.

- Jika nilai $\mathrm{R} / \mathrm{C}$ ratio sama dengan satu $(\mathrm{R} / \mathrm{C}=1)$ makausahatani tersebut impas atau tidak untung/tidak rugi untuk dilaksanakan.

2. Untuk menjawab penelitian yang kedua yaitu:

- Untuk mengetahui perbedaan dalam pendapatan antara pendapatan usahatani kopi pemetikan sistem selektif dangan sistem racutan, dilakukan uji perbandingan dengan menggunakan rumus uji $\mathrm{t}$ sebagai berikut (sugiyono, 2012):

$$
t=\frac{\overline{X_{1}}-\overline{X_{2}}}{\sqrt{\frac{\left(n_{1}-1\right) s_{1}^{2}+\left(n_{2}-1\right) s_{2}^{2}}{n_{1}+n_{2}-2}\left(\frac{1}{n_{1}}+\frac{1}{n_{2}}\right)}}
$$

Keterangan :

$\mathrm{T}=$ Nilai $\mathrm{t}$ hitung

$\bar{X}_{1}=$ Rata rata nilai sistem racutan

$\bar{X}_{2}=$ Rata rata nilai sistem selektif

$S_{1}^{2}=$ Varians sistem racutan

$S_{2}^{2}=$ Varians sistem selektif

$n_{1}=$ Banyaknya subjek sistem racutan

$n_{2}=$ Banyaknya subjek sistem selektif

Kaidah:

t_hit $>$ t_tabel $=$ Ha diterima Ho ditolak t_hit $<$ t_tabel = Ha ditolak Ho diterima

3. Untuk menjawab penelitian yang ketiga yaitu:

- Untuk perbandingan antara net benefit yang telah di discount faktor positif dengan net benefit yang telah di discount faktor negatif menggunakan rumus

Kaidah :

$$
\mathrm{Net} \mathrm{B} / \mathrm{C}=\frac{\sum N \bar{B}(+)}{\sum N \bar{B}(-)}
$$

Net B/C > 1, Maka usaha tersebut layak/feasieble

Net $B / C<1$, Maka usaha tersebut tidak layak/ Non feasieble

Net $\mathrm{B} / \mathrm{C}=1$, Maka usaha tersebut impas/Break Event Point

Menurut Ibrahim , 2009 untuk menghitung tingkat investasi/nilai kini

$$
N P V=\sum_{i=1}^{n} \bar{B}-\bar{C}
$$

Dimana :

$\mathrm{NB}=$ Net Benefit $($ Benefit - Cost $)$

$\mathrm{C}=$ Biaya Investasi + Biaya Operasional

$\bar{B}=$ Benefit Yang Telah di discount

$\bar{c}=$ Cost Yang Telah di discount

$\mathrm{i}=$ Cofounding Faktor

$\mathrm{n}=$ Tahun (Waktu)

Kaidah:

NPV $>0$ (nol) $\rightarrow$ usaha layak (feasible) untuk dilaksanakan

$\mathrm{NPV}<0($ nol $) \rightarrow$ usaha tidak layak (feasible) untuk dilaksanakan

$\mathrm{NPV}=0(\mathrm{nol}) \rightarrow$ usaha berada dalam keadaan BEP

Untuk menghitung tingkat bunga yang berlaku kini

$$
\mathrm{IRR}=i_{1}+\frac{N P V 1}{\text { NPVP1-NPV2 }} X\left(i_{2}-i_{1}\right)
$$

Keterangan :

$\mathrm{i}_{1} \quad$ : Cofounding Faktor Terendah

$\mathrm{i}_{2} \quad$ : Cofounding Faktor Tertinggi

NPV1 : Net Persent Value Positive

NPV2 : Net Persent Value Negative

SOCC: Social Oportunity Cost of Capital Kaidah: (Tingkat Bunga Berlaku Kini)

IRR $>$ SOCC $\rightarrow$ Maka usaha feasible/layak di teruskan

IRR $<$ SOCC $\rightarrow$ Maka usaha tidak feasible/tidak layak di teruskan

$\mathrm{IRR}=\mathrm{SOCC} \rightarrow$ Maka Break Event Point/Inpas 


\section{HASIL DAN PEMBAHASAN}

\section{A. Analisis Usaha}

\section{Analisis Penggunaan Biaya}

Suatu usaha memerlukan berbagai aktivitas yang telah direncanakan. Dari semua rangkaian aktivitas tersebut tentu memerlukan biaya yang harus dikeluarkan agar usaha yang direncanakan dapat berjalan dengan lancar. Oleh karena itu setiap usaha memiliki struktur biaya yang terdiri dari biaya tetap dan biaya variabel yang disebut dengan biaya produksi atau biaya total (Sjarkowi dan Marwan, 2004).

Menurut Mulyadi (2007), biaya dalam arti luas didefinisikan sebagai pengorbanan sumber ekonomi, yang diukur satuan uang yang telah terjadi atau kemungkinan akan terjadi untuk mencapai tujuan tertentu. Sedangkan definisi biaya dalam arti sempit adalah merupakan bagian dari harga pokok yang dikorbankan dalam hal usaha untuk memperoleh penghasilan.

Besaran penggunaan biaya usahatani kopi di Kabupaten OKU Selatan, yang terdiri dari penggunaan biaya tetap (Fixed Cost), Biaya Tidak Tetap (Variabel Cost) yang juga termasuk dari penggunaan biaya tenaga kerja, besaran penggunaan biaya usahatani kopi di Kabupaten OKU Selatan, sebagaimana pada tabel berikut:

Tabel 3. Kebutuhan Biaya Produksi Usahatani kopi di Kabupaten OKU Selatan

\begin{tabular}{|c|c|c|c|}
\hline \multirow[b]{2}{*}{ No } & \multirow[b]{2}{*}{ Uraian Biaya } & \multicolumn{2}{|c|}{ Penggunaan Biaya } \\
\hline & & Sistem Racutan & Sistem Selektif \\
\hline \multicolumn{4}{|c|}{1 Biaya Tetap/Alat } \\
\hline & Cangkul & 7.600 & 7.454 \\
\hline & Sabit & 10.503 & 7.987 \\
\hline & Gunting Tunas & 7.634 & 6.908 \\
\hline & Sub Total & 25.737 & 22.350 \\
\hline \multirow[t]{7}{*}{2} & Sarana Produksi & & \\
\hline & Herbisida & 239.523 & 224.154 \\
\hline & Insektisida & 161.648 & 115.169 \\
\hline & Pupuk Urea & 654.438 & 648.043 \\
\hline & Pupuk Ponska & 684.410 & 735.487 \\
\hline & Karung & 224.804 & 184.271 \\
\hline & Sub Total & 1.964 .823 & 1.907 .124 \\
\hline & Tenaga Kerja & & \\
\hline & Pemupukan & 574.074 & 600.000 \\
\hline & Pengendalian OPT & 168.519 & 200.000 \\
\hline & Pemetikan & 2.027 .778 & 4.155 .882 \\
\hline & Transportasi & 488.704 & 400.588 \\
\hline & Penjemuran & 977.407 & 801.176 \\
\hline & Penggilingan & 2.932 .222 & 2.403 .529 \\
\hline & Sub Jumlah & 7.168 .704 & 8.561 .176 \\
\hline & Jumlah (LG) & 9.159 .264 & 10.490 .650 \\
\hline & Jumlah (Ha) & 7.578 .429 & 8.806 .712 \\
\hline
\end{tabular}

Sumber: Olahan Data Primer, 2013.
Berdasarkan olahan data primer pada tabel diatas, diperoleh rata-rata dari 27 sampel petani contoh usahatani kopi dengan sistem pemetikan racutan dalam penggunaan biaya produksi berupa penggunaan biaya tetap rata-rata setiap proses produksinya sebesar Rp 25.737,-/tahun. Pada penggunaan biaya sarana produksi sebesar $\mathrm{Rp}$ 1.964.823,-/LG, sedangkan penggunaan biaya tenaga kerja sebesar Rp 9.159.264,-/LG, maka total biaya usahatani kopi sebesar Rp 9.159.264,/LG dan sebesar Rp 7.578.429,-/Ha.

Sedangkan dari rata-rata dari 17 sampel petani contoh usahatani kopi dengan sistem pemetikan selektif dalam penggunaan dalam penggunaan biaya produksi berupa penggunaan biaya tetap rata-rata setiap proses produksinya sebesar Rp 22.350 ,-/tahun. Pada penggunaan biaya sarana produksi sebesar Rp 1.907.124,-/LG, sedangkan penggunaan biaya tenaga kerja sebesar Rp 8.561.176,-/LG, maka total biaya usahatani kopi sebesar Rp 10.490.650,-/LG dan sebesar Rp 8.806.712,-/Ha.

2. Produksi, Harga, dan Penerimaan

Hasil produksi merupakan hasil usaha pengolahan usahatani kopi yang dinyatakan dengan satuan barang yang memiliki harga/nilai jual, sedangkan penerimaan adalah jumlah produksi dalam satuan fisik dikali dengan harga jual persatuan fisik. Penerimaan tunai usahatani didefinisikan sebagai nilai uang yang diterima, besarnya penerimaan yang diperoleh petani dari hasil usahatani antara satu dengan yang lainnya berbeda-beda walaupun luas lahan usaha yang mereka usahakan adalah sama juga sejenis, yang diusahakan juga sama.

Tabel 4. Jumlah Produksi, Harga Jual dan Penerimaan serta Pendapatan Usahatani kopi di Kabupaten OKU Selatan.

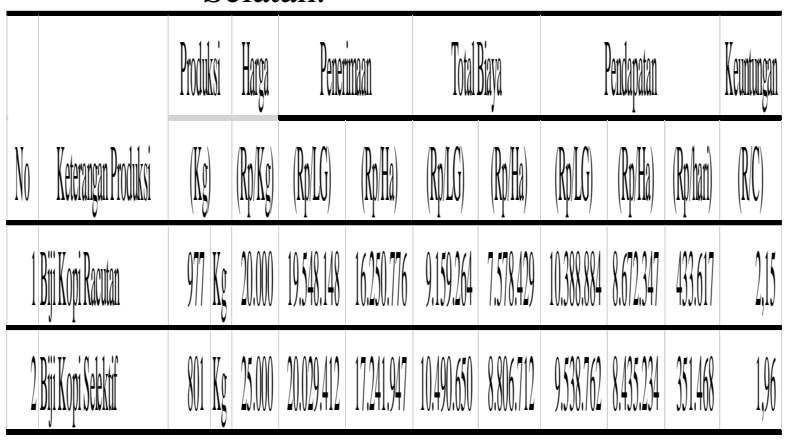

Sumber: Olahan Data Primer, 2013.

a. Sistem Pemetikan Racutan

Rata-rata dari 27 sampel petani contoh jumlah produksi biji kopi $(\mathrm{Kg} / \mathrm{LG})$, harga jual $(\mathrm{Rp} / \mathrm{Kg})$ dan besarnya perolehan penerimaan (Rp/LG) dikonversikan ke $(\mathrm{Rp} / \mathrm{Ha})$, pada usahatani kopi di 
Kabupaten OKU Selatan, sebagaimana pada tabel berikut:

Berdasarkan hasil olahan data primer pada tabel diatas, diperoleh besaran jumlah produksi, harga jual dan penerimaan, di peroleh jumlah produksi biji kopi rata-rata sebanyak $977 \mathrm{Kg}$ dengan harga jual rata-rata yang berlaku sebesar Rp $20.000,-/ \mathrm{Kg}$, maka petani memperoleh penerimaan sebesar Rp 19.548.148,-/Lg dan Sebesar Rp 16.250.776,-/Ha.

b. Sistem Pemetikan Selektif

Rata-rata dari 17 sampel petani contoh jumlah produksi biji kopi $(\mathrm{Kg} / \mathrm{LG})$, harga jual $(\mathrm{Rp} / \mathrm{Kg})$ dan besarnya perolehan penerimaan $(\mathrm{Rp} / \mathrm{LG}) \mathrm{di}$ konversikan ke ( $\mathrm{Rp} / \mathrm{Ha})$, pada usahatani kopi di Kabupaten OKU Selatan.

Berdasarkan hasil olahan data primer pada tabel diatas, diperoleh besaran jumlah produksi, harga jual dan penerimaan, di peroleh jumlah produksi biji kopi rata-rata sebanyak $801 \mathrm{Kg}$ dengan harga jual rata-rata yang berlaku sebesar Rp $25.000,-/ \mathrm{Kg}$, maka petani memperoleh penerimaan sebesar $\mathrm{Rp}$ 20.029.412,-/LG dan sebesar Rp 17.241.947,-/Ha.

3. Analisis Pendapatan

Pada umumnya pendapatan usahatani kopi yang bersumber dari penjualan biji kopi tidak stabil, selalu berubah-ubah, sekali waktu bisa lebih besar dan waktu lain bisa lebih kecil. Dalam hal ini perubahan harga sangat penting dipelajari, karena harga sangat berpengaruh pada usahatani kopi.

Besar kecilnya nilai penerimaan dan penggunaan biaya usaha sangat mempengaruhi besar kecilnya pendapatan, karena nilai pendapatan merupakan selisih total penerimaan (Total Revenue) dengan total biaya (Total Cost) yang digunakan dalam suatu usaha untuk memperoleh suatu keuntungan atau kegunaan, besarnya pendapatan usahatani kopi di Kabupaten OKU Selatan.

a. Sistem Pemetikan Racutan

Berdasarkan hasil olahan dari data primer pada tabel diatas, rata-rata dari 27 sampel petani contoh yang melakukan pemanenan dengan menggunakan sistem racutan, besarnya perolehan penerimaan usahatani kopi rata-rata sebesar Rp 19.548.148,-/LG dan sebesar Rp 16.250.776,/Ha , nilai tersebut lebih besar dari penggunaan biaya sebesar Rp 9.159.264,-/LG dan sebesar Rp 7.578.429,-/Ha, maka usahatani memperoleh pendapatan sebesar $\mathrm{Rp}$ 10.388.884,-/LG dan sebesar Rp. 8.672.347,-/Ha. Dengan memperoleh nilai $\mathrm{R} / \mathrm{C}$ sebesar 2,15 yang artinya usahatani kopi memberikan keuntungan sebesar Rp 1,15,dalam setiap 1 rupiah modal usahatani yang digunakan.

\section{b. Sistem Pemetikan Selektif}

Berdasarkan hasil olahan dari data primer pada tabel diatas, rata-rata dari 17 sampel petani contoh yang melakukan pemanenan dengan menggunakan sistem selektif, besarnya perolehan penerimaan usahatani kopi rata-rata sebesar Rp 20.029.412,-/LG dan sebesar Rp 17.241.947,-/Ha, nilai tersebut lebih besar dari penggunaan biaya sebesar Rp 10.490.650,-/LG dan sebesar Rp 8.806.712,-/Ha, maka usahatani kopi memperoleh pendapatan sebesar Rp 9.538.762,-/LG dan sebesar Rp 8.435.234,-/Ha. Dengan memperoleh nilai $\mathrm{R} / \mathrm{C}$ sebesar 1,96 yang artinya usahatani kopi memberikan keuntungan sebesar Rp 0,96,dalam setiap 1 rupiah modal usahatani yang digunakan.

4. Analisis Perbandingan Pendapatan

Analisis komparasi digunakan untuk mengetahui jauh mana tingkat perbedaan dalam pendapatan antara usahtani kopi sistem pemetikan racutan dan sistem selektif, analisis komparasi antara usahatani kopi sistem pemetikan racutan dan sistem selektif, uji komparasi menggunakan analisis uji t, analisis uji t pada usahatani kopi sistem pemetikan racutan dan sistem selektif, sebagaimana berikut:

$$
\begin{aligned}
& t=\frac{\overline{X_{1}}-\overline{X_{2}}}{\sqrt{\frac{\left(n_{1}-1\right) S_{1}^{2}+\left(n_{2}-1\right) S_{2}^{2}}{n_{1}+n_{2}-2}\left(\frac{1}{n_{1}}+\frac{1}{n_{2}}\right)}} \\
& t=\frac{433.617-351.468}{\sqrt{\frac{(27-1) 1.522 .266 .524+(17-1) 1.080 .929 .528}{27+17-2}\left(\frac{1}{27}+\frac{1}{17}\right)}} \\
& t=\frac{212 . \overline{323}}{\sqrt{\frac{39.578 .929 .612+17.294 .872 .442}{42}(0,096)}} \\
& t=\frac{212.323}{\sqrt{129.808 .450}} \\
& t=18,636 \\
& \text { t_tabel }=2,021 \text { dengan kesalahan 0,025 } \\
& \text { Keterangan : } \\
& \mathrm{t}=\text { Nilai } \mathrm{t} \text { hitung } \\
& \bar{X}_{1}=\text { Rata rata nilai sistem racutan } \\
& \bar{X}_{2}=\text { Rata rata nilai sistem selektif } \\
& S_{1}^{2}=\text { Varians sistem racutan } \\
& S_{2}^{2}=\text { Varians sistem selektif } \\
& n_{1}=\text { Banyaknya subjek sistem racutan } \\
& n_{2}=\text { Banyaknya subjek sistem selektif } \\
& \text { Kaidah : } \\
& \text { t_hit }>\text { t_tabel }=\text { Ha diterima Ho ditolak } \\
& \text { t_hit }<\text { t_tabel }=\text { Ha ditolak Ho diterima }
\end{aligned}
$$


Dimana berdasarkan hasil analisis perbandingan dalam pendapatan antara usahatani kopi sistem pemetikan racutan dan sistem selektif nilai uji t_hit diperoleh 18,636> t_tabel 2,021, maka dapat disimpulkan bahwa terdapat perbedaan yang highly significant antara pendapatan usahatani kopi sistem pemetikan racutan dan sistem selektif dengan kaidah $\mathrm{Ha}$ diterima Ho ditolak. Artinya bahwa pendapatan usahatani kopi sistem pemetikan racutan lebih besar dari sistem selektif.

5. Analisis Kelayakan Finansial

Analisis kelayakan finansial digunakan untuk mengetahui dan menentukan apakah usahatani kopi dengan sistem pemetikan racutan dan selektif layak untuk di usahakan dan dikembangkan atau tidak, keputusan tersebut akan di analisis berdasarkan tingkat kelayakan finanasial dengan menggunakan analisis NPV pada tingkat investasi atau nilai kini, IRR pada tingkat bunga yang berlaku kini dan Net B/C tingkat pendapatan atau keuntungan yang telah dikenakan biaya bunga bank. Analisis tingkat kelayakan secara finansial pada usahatani kopi di Kabupaten OKU Selatan, sebagaimana pada tabel berikut :

Tabel 5. Analisis Finansial Usahatani Kopi di Kabupaten OKU Selatan

\begin{tabular}{lllll}
\hline \multirow{2}{*}{ No } & \multicolumn{3}{c}{ Racutan } & \multicolumn{2}{c}{ Selektif } \\
\cline { 2 - 5 } & Tingkat Kelayakan & Jumlah Nilai & Tingkat Kelayakan & Jumlah Nilai \\
\hline 1 & NPVP (17\%) & 49.106 & NPVP (17\%) & 59.424 \\
2 & NPVN (27\%) & -2.160 & NPVN (33\%) & -3.588 \\
3 & Cofounding Faktor & $17 \%$ & Cofounding Faktor & $17 \%$ \\
& Terendah & & Terendah & \\
4 & Cofounding Faktor & $27 \%$ & Cofounding Faktor & $33 \%$ \\
& Tertinggi & & Tertinggi & \\
5 & Nilai IRR & $26,58 \%$ & Nilai IRR & $32,09 \%$ \\
6 & Net B/C & 0,21 & Net B/C & 0,24 \\
\hline
\end{tabular}

Sumber: Olahan Data Primer, 2013.

a.Sistem Pemetikan Racutan

Berdasarkan hasil olahan data primer pada tabel diatas, rata-rata dari 27 sampel petani contoh diperoleh nilai NPV discount faktor terendah $17 \%$ diperoleh nilai sebesar Rp 49.106,-/2 Tahun, pada nilai NPVN discount faktor $27 \%$ diperoleh diperoleh nilai negative sebesar - Rp 2.160,-/2 Tahun dengan nilai tingkat bunga yang berlaku kini IRR diperoleh 26,58\% nilai ini lebih besar dari SOCC $17 \%$ maka usaha dikategorikan layak untuk di usahakan dan dikembangkan jika dilakukan, pada analisis tingkat pendapatan atau keuntungan yang telah dikenakan biaya bunga bank Net B/C diperoleh sebesar 0,21, yang artinya usaha masih memberikan keuntungan sebesar 0,21 setelah dikenakan biaya bunga bank.

b. Sistem Pemetikan Selektif

Berdasarkan hasil olahan data primer pada tabel diatas, rata-rata dari 17 sampel petani contoh diperoleh nilai NPV discount faktor terendah $17 \%$ diperoleh nilai sebesar Rp 59.424,-/2 Tahun, pada nilai NPVN diskon faktor $33 \%$ diperoleh diperoleh nilai negatif sebesar - Rp 3.588,-/2 Tahun dengan nilai tingkat bunga yang berlaku kini IRR diperoleh 32,09\% nilai ini lebih besar dari SOCC $17 \%$ maka usaha dikategorikan layak untuk diusahakan dan dikembangkan, pada analisis tingkat pendapatan atau keuntungan yang telah dikenakan biaya bunga bank Net B/C diperoleh sebesar 0,24 , yang artinya usaha masih memberikan keuntungan sebesar 0,24 setelah dikenakan biaya bunga bank.

\section{IV.KESIMPULAN DAN SARAN}

\section{A. Kesimpulan}

Berdasarnya hasil penelitian dan analisis yang telah dilakukan, maka dapat ditarik kesimpulan sebagai berikut:

1. Perolehan Penerimaan usahatani kopi dengan pemetikan sistem racutan sebesar $\mathrm{Rp}$ 19.548.148,-/LG dan Rp 16.250.776,-/Ha, biaya sebesar Rp 9.159.264,-/LG dan Rp 7.578.429,-/Ha, maka usahatani kopi dengan sistem pemetikan racutan memperoleh pendapatan Rp 10.388.884,-/LG dan 8.672.347,-/Ha , sedangkan usatahani kopi dengan pemetikan sistem selektif memperoleh penerimaan sebesar Rp 20.029.412,-/LG dan $\mathrm{Rp}$ 17.241.947,-/Ha , biaya sebesar Rp 10.490.650,-/LG dan Rp 8.806.712,-/Ha, maka usahatani kopi sistem pemetikan selektif memperoleh pendapatan Rp 9.538.762,-/LG dan Rp 8.435.234,-/Ha.

2. Pada tingkat analisis keuntungan diperoleh rata-rata nilai $\mathrm{R} / \mathrm{C}$ lebih besar dari 1, dimana nilai $\mathrm{R} / \mathrm{C}$ sistem pemetikan racutan lebih besar yaitu sebesar 2,15 dari sistem pemetikan selektif yang hanya sebesar 1,96, maka usahatani kopi dengan sistem pemetikan racutan lebih banyak memberikan keuntungan bagi petani di Kabupaten OKU Selatan.

3. Pada tingkat perbandingan dalam pendapatan antara pendapatan usahatani kopi antara sistem racutan dengan selektif terdapat perbedaan 
yang sangat significant (highly significant), karena nilai t_hit 18,363> 2,018 yang artinya bahwa pendapatan usahatani kopi sistem racutan lebih besar dari sistem selektif.

4. Usahatani kopi sistem pemetikan racutan diperoleh nilai NPV diskon faktor terendah 17\% diperoleh nilai sebesar Rp 49.106,-/Tahun, pada nilai NPVN discount faktor $27 \%$ diperoleh diperoleh nilai sebesar $\mathrm{Rp} 2.160$,/Tahun dengan nilai tingkat bunga yang berlaku kini IRR diperoleh 26,58\% nilai ini lebih besar dari SOCC 17\% maka usaha dikategorikan layak untuk di usahakan, pada analisis tingkat pendapatan atau keuntungan yang telah dikenakan biaya bunga bank Net $\mathrm{B} / \mathrm{C}$ diperoleh sebesar 0,21 , yang artinya usaha masih memberikan keuntungan sebesar 0,21 setelah dikenakan biaya bunga bank. Sedangkan usahatani kopi sistem pemetikan selektif diperoleh nilai NPV diskon faktor terendah $17 \%$ diperoleh nilai sebesar $\mathrm{Rp}$ 59.424,-/Tahun, pada nilai NPVN discount faktor $33 \%$ diperoleh diperoleh nilai sebesar Rp 3.588,-/Tahun dengan nilai tingkat bunga yang berlaku kini IRR diperoleh 32,09\% nilai ini lebih besar dari SOCC 17\% maka usahatani kopi layak untuk diusahakan, pada analisis tingkat pendapatan atau keuntungan yang telah dikenakan biaya bunga bank Net B/C diperoleh sebesar 0,24 , yang artinya usaha masih memberikan keuntungan sebesar 0,24 setelah dikenakan biaya bunga bank.

\section{B. Saran}

Saran yang dapat diberikan dari hasil penelitian yang telah dilakukan adalah:

1. Adanya pengolahan biji kopi lebih lanjut.

2. Pengembangan usaha kopi luwak pada kopi sistem selektif dalam upaya peningkatan pendapatan petani.

\section{DAFTAR PUSTAKA}

Apriani, D. 2005. Pengaruh Penggunaan Faktor Produksi dan Perlakuan Pengeringan terhadap Pendapatan Usahatani Kopi di Kecamatan Kota Agung Kabupaten Lahat. Skripsi Fakultas Pertanian Universitas Sriwijaya. Indralaya.

Arsyad, L. 2003. Ekonomi Manajerial. Edisi Kelima. Penerbit Balai Pustaka. FE. UGM. Jogjakarta.
Azmi, 2007. Riset Keuangan. PT. Gramedia Pustaka Utama. Jakarta

Badan Pusat Statistik. 2010. Direktori Industri Pengolahan (Manufacturing Industry Directory) Indonesia 2010. Jakarta: Badan Pusat Statistik.

Bambang dan Kartosapoetro. 1988. Pengantar Ekonomi Produksi. Bina Aksara. Jakarta.

Boyd,,W. 1998. Manajemen Pemasaran. Erlangga. Jakarta

Bustami Bastian \& Nurlela. (2010). Akuntansi Biaya. Yogyakarta; Graha Ilmu

Daniel. M. 2002. Pengantar Ekonomi Pertanian. Bumi Aksara. Jakarta

Djamali RA. 2000. Manajemen Usahatani. Departemen Pendidikan Nasional, Politeknik Pertanian Negeri Jember, Jurusan Manajemen Agribisnis : Jember.

Firdaus. 2008. Manajemen Agribisnis.bumi Aksara, Jakarta

Hasan. 2010. Dasar-Dasar Statistika Terapan. Fakultas Tarbiyah. Semarang

Hansen \& Women, 2005, Manajemen Biaya,http//www. Devisi biaya.co.id

Harmoni, A. 2007. Analisis Kriteria Investasi. Gunadarma. Jakarta

Hernanto. F. 1996. Ilmu Usaha tani. Penebar Swadaya. Jakarta

Hoffman, James. 2014. The World Atlas of Coffee: From Beans to Brewing - Coffees Explored, Explained and Enjoyed. Octopus Publishing Group Limited. London.

Hutahean, B. 2006. Relevasi Kesesuaian Lahan Terhadap Produksi Kopi Serta Pendapatan Petani dan Pendapatan Daerah OKU Selatan. Skripsi Fakultas Pertanian Universitas Sriwijaya. Indralaya.

Hansen dan Mowen. 2005. Manajemen Biaya. http://sutondoscript.blogspot.com

Hilmawan, Hilman. 2013. Makalah Kopi. (http://hilmanhilmawan3.blogspot.com). 
Ibrahim Y. 2009. Study Kelayakan Bisnis. Rineka. Jakarta

Junaidi. Y., M. Antoni. 2007. Analisis Potensi Peningkatan Pendapatan Petani Melalui Pola Tanam Disversifikasi Usahatani Kopi di Sentra Produksi Utama Sumatera Selatan. Hibah Penelitian Program PHK A2. Jurusan Sosial Ekonomi Pertanian Universitas Sriwijaya.

Kadarsan, W.H. 2005. Keuangan Pertanian dan Pembiayaan Perusahaan Agribisnis. Gramedia Pustaka Utama. Jakarta.

Kadarsan, 2007. Dasar-Dasar Manajemen. LP3ES. Jakarta

Kartasapoetra, AG. 1996. Pengantar ekonomi Produksi. BinaAksana. Jakarta

1998. Manajemen Pertanian dalam Agribisnis. Bina Aksara. Jakarta

2003. Pengantar Ekonomi Produksi. Bina Aksana. Jakarta

Kotler, P. 2002. Manajemen Pemasaran, Prenhallindo. Jakarta

Kristianto, Nurhayati dan Atmadja. 2008. Pemasaran Produksi. Jakarta

Limbong, WH dan P, Sitorus. 1997. Pengantar Tataniaga Pertanian. Jurusan Sosial Ekonomi Pertanian Institut Pertanian IPB. Bogor

Manulung, 2003. Harga Dalam Proses Produksi. Grafindo. Jakarta

Misbahuddin. 2013. Analisis Data penelitian dengan Statistik. Bumi Aksara. Jakarta

Mubyarto. 1990.Pengantar ekonomi Pertanian. Lembaga Penelitian Pendidikan dan Penerangan Ekonimi dan Sosial (LP3ES). Jakarta

1995. Pengantar Ekonomi Pertanian. Lembaga Penelitian Pendidikan dan Penerangan Ekonomi dan Sosial (LP3ES). Jakarta.

Mulyadi. 2007. Akuntansi Biaya, edisi ke-5. Graha Ilmu. Yogyakarta
2009. Sistem Akutansi. Baldad Grafis

Press

Najiyati, Sdan Danarti. 2004. Kopi, Budidaya dan Penanganan Pasca Panen. Penebar Swadaya. Jakarta.

Nitisemito. 1997.ManajemenPemasaran. PT Linda Karya. Bandung

Panggabean, Edy. 2011. Buku Pintar Kopi. PT. AgroMedia Pustaka. Jakarta.

Rahardjo, Pudji. 2012. Panduan Budidaya dan Pengolahan Kopi Arabika dan Robusta. Penebar Swadaya. Jakarta

Rahardi. F, 2003. Cerdas Beragrobisnis, Agromedia Pustaka Jakarta.

Rahim. S. E. 1999. Meningkatkan Daya Dukung Sumberdaya Lahan. UNSRI. Palembang

Ricky. W. dan Ronal dan J Ebert. 2006. Bisnis Akutansi Manajemen. Erlangga. Jakarta

Ridwansyah, 2003. Pengolahan Kopi. Jurusan Teknologi Pertanian. Fakultas Pertanian, Universitas Sumatra Utara. (C2003 Digitized by USU digital library.

Rosidi, S. 2001. Pengantar Teori Ekonomi. PT. Raja Graffindo Persada. Jakarta.

Samoelson dan Nardhous. 2008. Pengantar Ekonomi Makro. Erlangga. Jakarta.

Sangadji, Em dan Sopiah. 2010. Metode Penelitian. Penerbit Andi. Yogyakarta.

Sanusi, A. 2002. Analisis Efisiensi Pemasaran Usahatani Kopi di Kabupaten Lahat dan Kota Pagar Alam. Tesis Program Magister Ilmu Ekonomi Program Pasca Sarjana. Universitas Sriwijaya. Palembang (tidak dipublikasikan).

Saragih, B. 2001, Pengembangan Agribisnis Dalam Pembangunan Nasional Menghadapi Abad ke 21. http://PengembanganSistemAgribisnis.

, 2001, Suara Dari Bogor Membangun Sistim Agribisnis, Yayasan USESE bekerjasam dengan Sucofindo. 
2007, Agribisnis Paradigma Baru Pertaniaan, Agrina, Yayasan Mulia Persada Indonesia.

Shinta, A. 2011. Ilmu Usahatani. UB Press: Malang

Sjarkowi, F dan Sufri, M. 2004. Manajemen Agribisnis. CV. Baldad Grafiti Press. Palembang

Sjarkowi dan Marwan. 2010. Manajemen Agribisnis. CV Baldad Grafiti Press. Palembang.

Sjarkowi, F. 2010. Manajemen Agribisnis. CV. Baldad Grafiti Press. Palembang.

Soeharjo dan Patong. 2003. Sendi-Sendi Pokok Ekonomi Usahatani. Departemen IlmuIlmu Sosial Ekonomi Pertanian Fakultas Pertanian Bogor. Bogor

Soekartawi. 1991. Prinsip Dasar Komunikasi Pertanian. UI Press. Jakarta 2002. Analisis Usahatani. UI - Press.

Jakarta

2003. Teori Ekonomi Produksi. Raja

Grafindo Persada. Jakarta

2004. Prinsip Dasar Ekonomi Pertanian. Raja Grafindo Persada.

Soetono. 1998. Penyerapan Tenaga Kerja Luar Sektor Pertanian di Pedesaan. Survey Agro Ekonomi. Bogor

Sofyan. 2004. Manajemen Produksi dan Operasi. Lembaga Fakultas Ekonomi UI. Jakarta

Sri Najiyati dan Danarti. 2004 . Budidaya Tanaman Kopi dan Penanganan Pasca Panen. Penebar Swadaya. Jakarta

Starfarm. 2010a. Pengolahan Pasca Panen Kopi. (http://www.starfarmagris.co.cc /2009/06/pengolahanpasca-panenkopi.html)
Starfarm. 2010b. Pengolahan Kopi Secara basah. http://www.starfarmagris.co.cc /2009/06/pengolahankopi-cara-basah.html.

Stice. 2009. Akuntansi Keuangan. Salemba Empat. Jakarta

Sugiyono. 2001. Statistika untuk Penelitian, Bandung: Alfabeta.

2007. Metode Penelitian Kuantitatif. Kualitatif dan R\&D. Ed Ke 2. CV Alfabet. Bandung.

Suratiyah, K. 2006. Ilmu Usahatani. Penebar Swadaya. Jakarta.

Suwardjono. 2011. Teori Akuntansi: Perekayasaan Pelaporan Keuangan. Salemba Empat. Jakarta

Teken dan Aswi. 1997. Faktor-faktor Produksi. Gramedia. Jakarta

Teken, I. B. dan Asnawi, S. 1981. Teori Ekonomi Mikro. Departemen Ilmu Sosial Ekonomi. IPB. Bogor

2004. Teori Ekonomi Mikro. Departemen Ilmu-Ilmu Sosial Ekonomi. Institut Pertanian Bogor. Bogor.

Tohir, K. A. Usahatani Indonesia. Edisi 1. PT. Renika Cipta. Jakarta

Umar, H. 1994. Studi Kelayakan Bisnis. Raja Grafindo Persada. Jakarta.

Usman. N. 1989. Pedoman Praktis Budidaya Tanaman Perkebunan. PD. Mahota. Jakarta.

Yusianto. 2010. Usahatani Kopi Varietas Arabika dan Robusta. Jakarta. PT Gravindo Persada 